\title{
Standard Treatment
}

National Cancer Institute

\section{Source}

National Cancer Institute. Standard Treatment. NCI Thesaurus. Code C142696.

A therapy approved by a health regulatory authority and in wide use, which is considered to be the standard of care for the management of a specific disease or condition. 